\title{
The Effect of Bacillus subtilis on The Bacterial Content in Rabbits Caeci Eman, F. Farag ${ }^{1}$ and G. A. Abdel-Alim ${ }^{2} *$ \\ ${ }^{1}$ Animal Health Research Institute, Dokki, Agricultural Research Center (ARC), Egypt. \\ ${ }^{2}$ Department of Poultry diseases, Fac. of Vet. Med., Cairo University, Egypt. \\ *Corresponding Author, Gomaa Abdullalim, E-mail: g.abdullalim@vet.cu.edu.eg
}

\begin{abstract}
In the present study, the effect of B. subtilis $\left(10^{7} \mathrm{cfu} / \mathrm{gm}\right)$ supplemented to the basal diet of two groups of New Zealand rabbit of 28 days ( $\mathrm{n}=15 /$ group) on the count of commensal microflora (Bifidobacteria and Lactobacilli spp.) and some opportunistic pathogens (E. coli and $C$. perfringens type A) in the rabbit caeci was investigated. Results indicated that the count of Bifidobacteria and Lactobacilli spp. are significantly increased at all intervals (7, 14, 28 and 40 days post supplementation) in the supplemented group compared with non-supplemented group with $\mathrm{P}<$ 0.001 . On the other hand, there is a significant decrease in the count of $E$. coli and $C$. perfringens specially at 40 days post supplementation from $(5.8 \log 10 \mathrm{cfu} \pm 0.06)$ to $(3.1 \log 10 \mathrm{cfu} \pm 0.07)$ and from $(4.8 \log 10 \mathrm{cfu}$ $\pm 0.09)$ to $(2.3 \log 10 \mathrm{cfu} \pm 0.09)$ respectively with $\mathrm{P}<0.001$. B. subtilis proved to be tolerant to the simulated gastric and intestinal juice for one hour (100\% tolerance). However, after two hours, the tolerance to the gastric juice decreased to $70 \%$, with no effect of the artificial intestinal juice on the viability of the organism. In vitro, the antimicrobial effect of $B$. subtilis on $C$. perfringens type A by well diffusion method showed an inhibition zone of $10 \mathrm{~mm}$. Results of in vitro effect of B. subtilis on $C$. perfringens count showed that at $10^{3}$ dilutions of $C$. perfringens, its count was reduced $2.1 \times 10^{5}$ to $3 \times 10^{4}$ after adding $B$. subtilis, while at dilution of $10^{2}$, the count was reduced from $2.4 \times 10^{5}$ to $7 \times 10^{3} \mathrm{cfu} / \mathrm{ml}$ after adding $B$. subtilis. It could be concluded that $B$. subtilis can be used as a probiotic in rabbits ration due to its ability to increase the commensal microflora count beside its antibacterial effect against some opportunistic pathogens.
\end{abstract}

\section{Original Article: \\ https://dx.doi.org/10.21608/javs.2020.1 $\underline{17995}$}

\section{Received :26 July, 2020. \\ Accepted :23 Aug., 2020. \\ Published in October, 2020.}

\begin{abstract}
This is an open access article under the term of the Creative Commons Attribution 4.0 (CC-BY) International License . To view a copy of this license, visit http://creativecommons.org/licenses/by/4.0/
\end{abstract}

Keywords: B. subtilis, Caeci, C. perfringens, E. coli, Probiotics, Rabbit. $\quad J$. Appl. Vet. Sci., 5(4): 10 - 16.

\section{INTRODUCTION}

In developing countries, livestock production provides food and play an important role in economic improvement and is considered as a significant income source for many family farms. In the past, the use of antibiotic growth promoters (AGPs) in large scale to animal feed has contributed to the increase in livestock production. However, the over-use of AGPs resulted in the emergence of multidrug-resistant microorganisms and consequently prohibited by the European Union which introduced a total ban on AGPs in 2006 (Castanon, 2007).

The prohibition on the sub-therapeutic use of antibiotics in animal feed resulted in decreased animal production (Cheng et al., 2014) due to higher rates of infections in livestock and has also increased the risk of food-borne diseases in consumers (Hao et al., 2014). Several replacements/alternatives have been proposed to overcome the problems associated with the ban of AGPs on livestock production (Cheng et al., 2014). The use of probiotics is considered as one strategy that has proven effective.

In the last decade, several strains of some Bacillus spp. are currently used as probiotic dietary supplements in animal feeds. Bacillus is a genus of Gram-positive, aerobic or facultatively anaerobic, endospore-forming bacteria. Bacillus spp. are saprophytes commonly associated with soil, water, dust and air In addition to an intestinal origin, Bacillus probiotics can also be isolated from other sources, including food, plants, marine algae, aquatic habitats and soil (Mingmongkolchai and Panbangred, 2018).

Spore-forming-Bacillus spp. Among a variety of bacterial species used as probiotics has been identified as an appropriate probiotic because its spores are resistant to harsh conditions and long-term storage 
at ambient temperature as well as an inhibition for pathogenic bacterial growth (Chen et al., 2013). Compared with other probiotic microorganisms, Bacillus spp. have many advantages as probiotic supplements in animal feed because of their ability to produce spores. In addition to heat stability, Bacillus sp. spores have the ability to survive the low $\mathrm{pH}$ of the gastric barrier. They can reach the small intestine to exert their probiotic properties (Cutting, 2011).

It was found that Bacillus spores germination occur in the small intestine (Cartman et al., 2008), and may induce their protective effect in the host through metabolically active mechanisms, such as secretion of antimicrobial substances and/or competition with pathogenic bacteria for essential nutrients (Duc et al., 2004). In addition to stimulating positive changes in the intestinal microflora, diarrhea recovery, increased body weight gain and feed efficiency were observed in the host when the animals were fed B. Subtle (Jiraphocakul et al., 1990).

Probiotics have been used widely in poultry production. Several studies were conducted to investigate the beneficiary effect of $B$. subtilis probiotics against $S$. Enteritidis or Clostridium perfringens (La Ragione and Woodward 2003), $C$. perfringens and Enterobacteriaceae (Jeong and Kim 2014), Campylobacter (Guyard-Nicodeme et al., 2016) and Salmonella colonization in broilers (Knap et al., 2011). An intensive system of rabbit production, especially during the weaning period, can cause many physiological and environmental stresses. These problems result in concentration and spreading of pathogens such as E. coli, coccidian and epizootic rabbit enteropathy which have adverse effects on growth performance, feed efficiency and rabbit health status (Bovera et al., 2010 and Licois et al., 2000).

Therefore, our study was conducted to investigate the beneficiary effect of $B$. subtilis as a feed supplement in rabbit feeding, and its effect on some commensal and opportunistic pathogens such as $E$. Coli and $C$. perfringes in rabbit caeci (in vivo) and to study its effect on $C$. perfringens type A (in vitro).

\section{MATERIALS AND METHODS}

\section{Bacterial strains and Media}

\section{Bacillus subtilis strain}

A reference commercial strain of $B$. subtilis (ATCC 10876) was kindly obtained from Food and Meat Hygiene Department in Animal Health Research Institute. It was aerobically cultured in trypton soya broth (TSB) supplemented with $1 \%(\mathrm{w} / \mathrm{v})$ yeast extract (TSBYE) and incubated for 18 hours at $37^{\circ} \mathrm{C}$ aerobically.

\section{Clostridium perfringens type A strain}

It was isolated from a case of enteritis in rabbits, the pathogenicity and toxicity of this isolate were tested for lethality and dermonecrotic reaction in Swiss mice and guinea pigs respectively (willis, 1977). C. perfringens isolate was anaerobically cultured in thioglycolate broth and incubated for 18 hours at $37^{\circ} \mathrm{C}$. Both $B$. subtilis and $C$. perfringens broth cultures were centrifuged (3000xg for $10 \mathrm{~min}$ ) and washed using sterile phosphate buffer saline (PBS) $\mathrm{pH}$ 7.4. In cell culture medium a final concentration of $107 \mathrm{cfu} / \mathrm{ml}$ was re-suspended for further testing

\section{Experimental design}

Study the effect of B. subtilis on bacterial content count in rabbit caeci:

To study the effect of B. subtilis on bacterial content in rabbit caeci in vivo, 30 healthy weaned New Zealand White male rabbits (28 day-old) were divided into 2 groups consisting of 15 rabbits each. Group 1 were fed with a basal diet supplemented with $10^{7} \mathrm{cfu} / \mathrm{gm}$ basal diet of $B$. subtilis, while rabbits of group 2 were fed with a basal diet only and served as a negative control group. All groups ran contemporaneously in a battery with sufficient room temperature, feed, and ventilation until the end of the experiment (6 weeks).

Intestinal samples were collected at 7, 14, 28 and 40 days post supplementation (3 samples/time) from each group for enumeration of some commensal and opportunistic pathogenic microorganisms as described by (Guo et al., 2017) as follows: The intestinal contents were serially diluted in $0.85 \%$ sterile saline solution and each dilution was plated in duplicate onto selective agar for each microorganism (eosin methylene blue for enumeration of $E$. coli, tryptose sulphate cycloserine agar for $C$. perfringens, MRS agar for Lactobacillus spp., and Bifidobacterium agar medium for Bifidobacterium spp.)

\section{Survival of Bacillus subtilis in a simulated gastro- intestinal juice}

A simulated gastrointestinal juice was made to investigate the survival of $B$. subtilis in these juices. The suspension of $2.3 \times 10^{7} \mathrm{cfu} / \mathrm{ml}$ of $B$. subtilis were inoculated into Trypton Soya Broth (TSB) and $\mathrm{pH}$ was adjusted to 2.5 by adding a hydrochloric acid solution with $1 \%$ pepsin (as gastric juice) or to 7.2 with $1 \%$ trypsin ( as intestinal juice) and incubated at $37^{\circ} \mathrm{C}$ for up to two hours. At 0,1 and 2 hours of incubation, 100 $\mu 1$ of the culture were removed and spread onto trypton soya agar plates in duplicate for cell number estimation as described by (Guo et al., 2017).

\section{Antimicrobial activity of $B$. subtilis}

The well diffusion method was performed on agar using cultured broth. The target strain $C$. perfringens in a concentration of $\left(10^{7} \mathrm{cfu} / \mathrm{ml}\right)$ was incorporated into agar $(1 \% \mathrm{w} / \mathrm{v})$ plates, mixed for uniformity and poured onto plates to solidify. Overnight culture of $B$. subtilis $\left(10^{8} \mathrm{cfu} / \mathrm{ml}\right)$ was transferred to holes $(5 \mathrm{~mm}$ in diameter) punched into 
the agar plates. The plates were then incubated anaerobically at $37^{\circ} \mathrm{C}$ for 24 hours and the antimicrobial inhibition zone was recorded as described by (Zhang et al., 2012).

\section{Effect of $B$. subtilis on $C$. perfringens count (in vitro)}

Clostridium perfringens suspension in PBS was prepared as $10^{5} \mathrm{cfu} / \mathrm{ml}$ using McFarland tube from which tenfold dilution was made, and $1 \mathrm{ml}$ of each dilution was dispensed in sterile Petri dishes then $10 \mathrm{ml}$ of molten tryptose sulphate cycloserine agar (TSC) was poured, mixed well and left to solidify before another layer was poured. All $C$. perfringens suspension dilutions were seed with $0.1 \mathrm{ml}$ of overnight culture of B. subtilis $\left(10^{7} \mathrm{cfu} / \mathrm{ml}\right)$ and incubated for 1 hour at $37^{\circ}$ $\mathrm{C}$ then cultured onto TSC agar as mentioned before. After solidification, the plates were incubated anaerobically at $37^{\circ} \mathrm{C}$ for 24 hours then enumerated as described by (Guo et al., 2017).

\section{Statistical Analysis}

Experimental data were assessed by one-way analysis of variance (ANOVA)-Duncan test using SPSS software statistical program (windows version 20.0, USA) to observe mean differences (SPSS 20.0, 2014). Data were expressed as mean $\pm S E$ when $(n=5)$ and were regarded as significant when $(\mathrm{P} \leq 0.05)$.

\section{RESULTS}

\section{Detection of $B$. subtilis effect on bacterial content in rabbit caeci}

It was found that the beneficial microflora e.g. Bifidobacterium and Lactobacillus spp. obviously increased in group treated with $B$. subtilis and the opportunistic pathogenic organisms count were decreased in this group. On the other hand, the control group nearly showed stability in the count of all microorganisms as shown in Table (1).

\section{Survival of Bacillus subtilis in simulated gastric and intestinal juices \\ Bacillus subtilis ATCC 10876 exhibited a good probiotic property in vitro including artificial gastric juice and intestinal juice. The strain can tolerate the alkalinity of the intestinal juice till 2 hours; however, it may show less tolerance with the acidity of gastric juice after 2 hours as shown in Table (2).}

\section{Effect of $B$. subtilis on $C$. perfringens type A count (in vitro)}

It was observed that, at $10^{3}$ dilutions, the count of $C$. perfringens culture was $2.1 \times 10^{5} \mathrm{cfu} / \mathrm{ml}$, however, when $B$. subtilis was added, the count of $C$. perfringens decreased to $3 \times 10^{4} \mathrm{cfu} / \mathrm{ml}$ (Figs. 1 and 2). On the other hand; when $C$. perfringens culture was at $10^{2}$ dilutions, its number reached $2.4 \times 10^{5} \mathrm{cfu} / \mathrm{ml}$ and decreased to $7 \times 10^{3} \mathrm{cfu} / \mathrm{ml}$ after treated with B. subtilis (Figs. $3 \& 4$ ).

\section{Antimicrobial activity of $B$. subtilis}

The sensitivity of $C$. perfringens against $B$. subtilis on tryptose sulphate cycloserine agar (TSC) was made and a zone of inhibition of about $10 \mathrm{~mm}$ has been formed. A sterile Trypricase soya yeast extract (TSY) broth was used as control negative in another well (Fig.5)

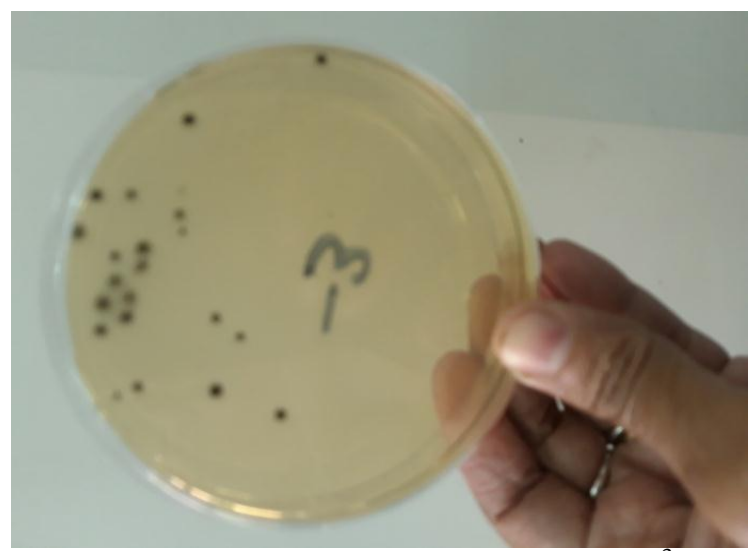

Fig. 1: count of C.perfringens diluted $10^{3}$ times without adding $B$. subtilis culture $\left(2.1 \times 10^{5} \mathrm{cfu} / \mathrm{ml}\right)$.

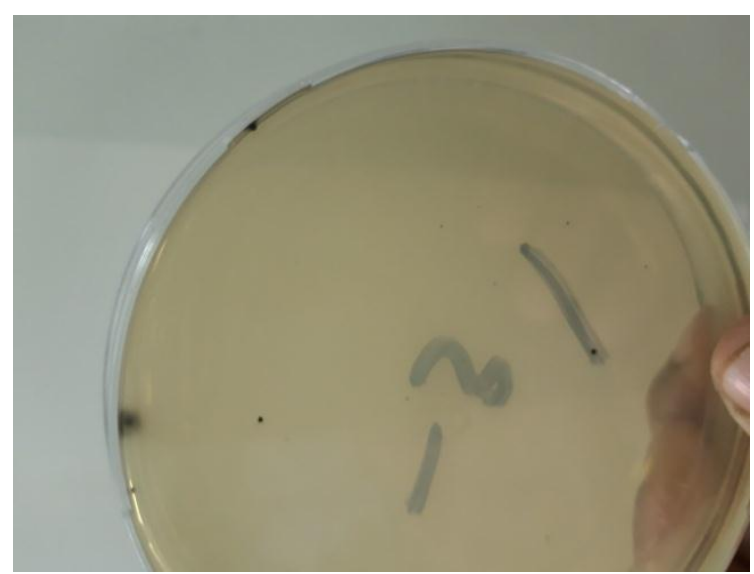

Fig.2: count of C.perfringens diluted $10^{3}$ times after adding $B$.subtlis culture $\left(3 \times 10^{4} \mathrm{cfu} / \mathrm{ml}\right)$

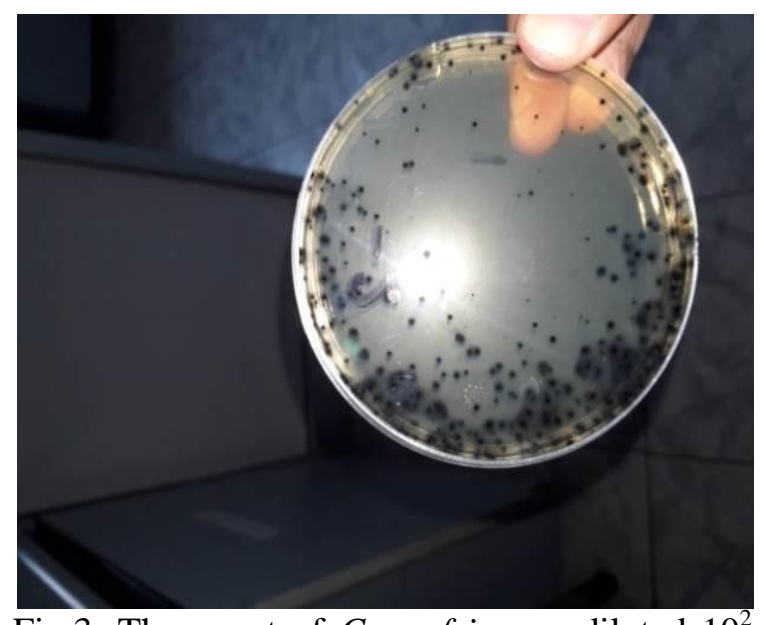

Fig.3: The count of $C$. perfringens diluted $10^{2}$ times without adding B. subtlis culture $\left(2.4 \times 10^{5} \mathrm{cfu} / \mathrm{ml}\right)$. 


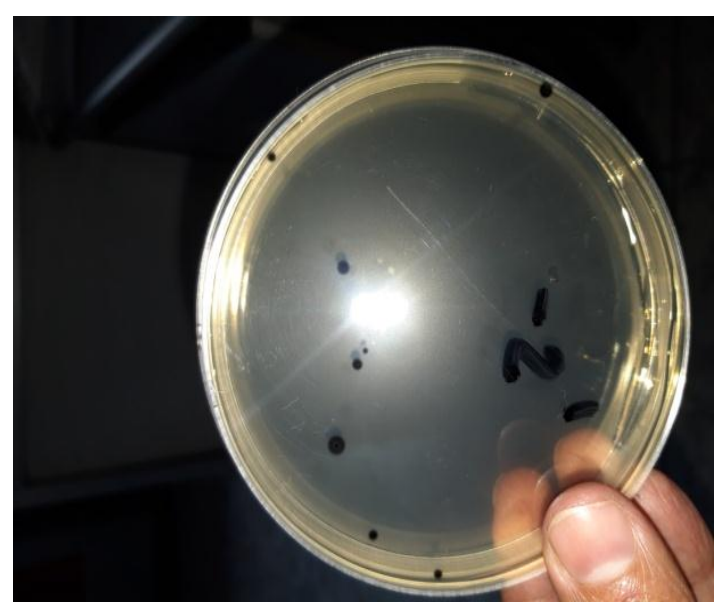

Fig.4: The count of $C$. perfringens diluted $10^{2}$ times after adding B. subtlis culture $\left(7 \times 10^{3} \mathrm{cfu} / \mathrm{ml}\right)$.

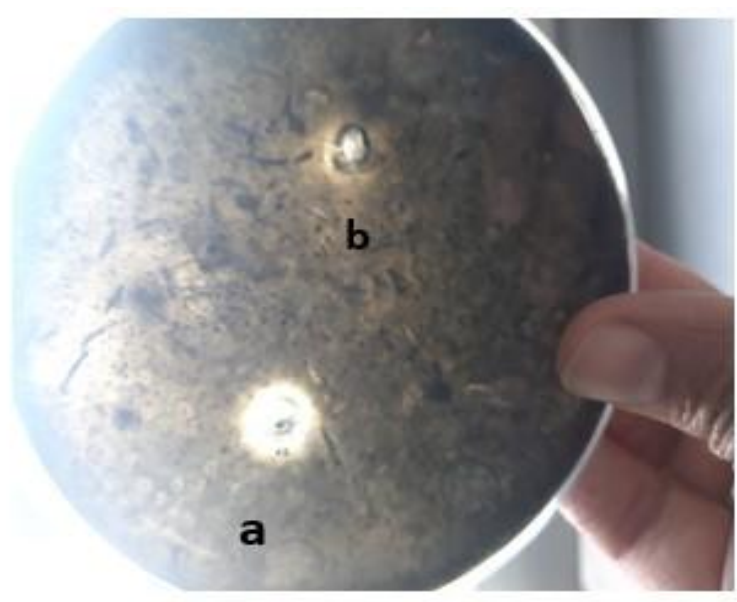

Fig.5: The sensitivity of $C$. perfringens against $B$. subtlis on TSC agar. (a) showing a zone of inhibition of $10 \mathrm{~mm}$. (b) Control negative using sterile TSB broth

Table 1: Enumeration of commensal and pathogenic bacteria in caeci of rabbits.

\begin{tabular}{|c|c|c|c|c|c|c|c|c|}
\hline \multirow{2}{*}{ Groups } & \multicolumn{8}{|c|}{$\begin{array}{l}\text { Count of commensal and pathogenic opportunistic } \\
\text { microorganisms in }\left(\log _{10}\right)\end{array}$} \\
\hline & \multicolumn{4}{|c|}{ Group 1} & \multicolumn{4}{|c|}{$\begin{array}{c}\text { Group2 } \\
\text { (Negative control) }\end{array}$} \\
\hline $\begin{array}{l}\text { day post } \\
\text { supplementation }\end{array}$ & 7 & 14 & 28 & 40 & 7 & 14 & 28 & 40 \\
\hline \multirow[t]{2}{*}{ E. coli } & $5.4 \pm$ & $5.3 \pm$ & $4.4 \pm$ & $3.1 \pm$ & $5.5 \pm$ & $5.2 \pm$ & $5.9 \pm$ & $5.8 \pm$ \\
\hline & 0.06 & 0.09 & $0.03 * * *$ & $0.07 * * *$ & 0.06 & 0.09 & $0.03 * * *$ & $0.06 * * *$ \\
\hline \multirow[t]{2}{*}{ C. perfringens } & $4.5 \pm$ & $3.5 \pm$ & $2.2 \pm$ & $2.3 \pm$ & $4.3 \pm$ & $5.7 \pm$ & $4.7 \pm$ & $4.8 \pm$ \\
\hline & $0.06^{*}$ & $0.07 * * *$ & $0.06^{* * *}$ & $0.09 * * *$ & $0.03 *$ & $0.1 * * *$ & $0.09 * * *$ & $0.09 * * *$ \\
\hline \multirow{2}{*}{$\begin{array}{l}\text { Bifidobacteriumsp } \\
p\end{array}$} & $7.8 \pm$ & $8.1 \pm$ & $9.0 \pm$ & $9.4 \pm$ & $7.1 \pm$ & $7.4 \pm$ & $7.6 \pm$ & $7.7 \pm$ \\
\hline & $0.06^{* * *}$ & $0.06 * * *$ & $0.06^{* * *}$ & $0.09 * * *$ & $0.06^{* * * *}$ & $0.03 * * *$ & $0.06^{* * *}$ & $0.06 * * *$ \\
\hline \multirow[t]{2}{*}{ Lactobacillus spp. } & $9.0 \pm$ & $8.9 \pm$ & $9.6 \pm$ & $9.7 \pm$ & $7.6 \pm$ & $7.8 \pm$ & $6.7 \pm$ & $7.8 \pm$ \\
\hline & $0.03 * * *$ & $0.03 * * *$ & $0.09 * * *$ & $0.06 * * *$ & $0.09 * * *$ & $0.03 * * *$ & $0.03 * * *$ & $0.03 * * *$ \\
\hline
\end{tabular}

${ }^{*} \mathrm{p}<0.05, * * \mathrm{p}<0.01, * * * \mathrm{p}<0.001$

Table 2: Survival rate of B. subtilis at artificial gastric juice and intestinal juice (\%) (The mean of count).

\begin{tabular}{|c|c|c|c|}
\hline Juice Time & 0 hour & 1 hour & 2 hours \\
\hline Gastric juice & $2.3 \times 10^{7}$ & $100 \%\left(1.8 \times 10^{7}\right)^{*}$ & $70 \%\left(1.6 \times 10^{6}\right)^{* *}$ \\
\hline Intestinal juice & $2.3 \times 10^{7}$ & $100 \%\left(1.9 \times 10^{7}\right)^{*}$ & $100 \%\left(1.7 \times 10^{7}\right)^{*}$ \\
\hline
\end{tabular}

* count not changed (complete tolerance)

** count changed (partial tolerance) 


\section{DISCUSSION}

Probiotics are safe alternative to antibiotics which will improve growth performance and act as therapeutically or prophylactically drugs, as antibiotics disturbs the normal microbial balance and beneficial bacteria (Simoneit et al., 2014) and (Sullivan et al., 2001). B. subtilis are considered to be suitable probiotics as they produce essential nutrients such as amino acids and vitamin $\mathrm{K}$ and $\mathrm{B}_{12}$, promoting growth performance and proliferation of beneficial bacteria as well (Cutting, 2011and Zhou et al., 2013). The effectiveness of probiotics depends largely on the dose ingested and bacterial strains, therefore, it is essential to determine the minimal effective dosage of probiotic strains (Mingmongkolchai and Panbangred, 2018).

In this study, the role of B. subtilis as a dietary probiotic in rabbit ration was investigated to determine its effect on some opportunistic pathogens as well as some beneficial commensal bacteria in the gut of rabbits. It was found that $B$. subtilis had a significant inhibitory effect on the count of pathogenic bacteria in the gut of rabbits as the count of $E$. coli as well as $C$. perfringens were decreased significantly throughout the experiment. These results are on line with Phuoc and Jamikorn (2017) who investigated the role of $B$. subtilis supplement on feed efficiency, growth performance and microbial population in the distal gastrointestinal tract of weaning rabbits and found that the average intestinal coliform populations were lowest $(\mathrm{P}<0.05)$ in the rabbits supplemented with $B$. subtilis than control.

Additionally; suppression of colonization and persistence of $S$ Enteritidis or $C$. perfringens was demonstrated in pre-dosing newly hatched specific pathogen-free chicks with a suspension of $1 \times 10^{9}$ spores of B. subtilis PY79 ${ }^{\mathrm{hr}}$. Moreover, S. Enteritidis shedding was also reduced significantly in the pre-dosed birds for the 36-days duration of the experiment (La Ragione and Woodward 2003). Similarly, Jeong and Kim (2014) showed that the number of $C$. perfringens and Enterobacteriaceae in the excreta is reduced when birds were fed B. subtilis C-3102.

Reduction in shedding of Campylobacter is observed in broilers fed B. subtilis C-3102, (GuyardNicodeme et al., 2016) and a significant reduction in Salmonella colonization in broilers fed with either $B$. cereus var toyoi (Toyocerin) (Vila et al., 2009) or $B$. subtilis DSM 17299(Knap et al., 2011). Supplementation of $B$. subtilis PB6 to broilers also resulted in a reduction in intestinal $C$. perfringens counts (Jayaraman et al., 2013).

It was found that the count of beneficial commensal bacteria (Bifidobacterium spp. and Lactobacillus spp.) significantly increased in B. subtilis supplemented group $(\mathrm{P}<0.001)$. Guo et al. (2017) found that the survival rate of the rabbits fed with $B$. subtilis was significantly higher than those in the control groups post infected with E. coli. It is worth to say that $B$. subtilis strains that do not have any probiotic activity or killed cells cannot produce digestive enzymes, vitamins and antibacterial substances, which were produced by probiotic. For that, it is speculated that strains without probiotic activity have no significant effects on growth performance, intestinal flora and disease resistance. The ability of B. subtilis to inhibit the adhesion of enterotoxic E. coli to the surface of intestinal epithelial cells and $S$. Enteritidis through competitive exclusion (CE) mechanism was reported by other investigators (Thirabunyanon and Thongwittaya, 2012; Ye et al., 2013).

Probiotics should also be excellent in adapting to acidic conditions in the stomach and alkalinity in the intestine to influence the gastrointestinal tract. The ability of the spores to survive at low $\mathrm{pH}$ of the gastric barrier and reach the small intestine to produce the probiotic effects was documented by Barbosa $\boldsymbol{e t} \boldsymbol{a l}$. (2005) and Cutting (2011) that accord with our findings as it was found that B.subtilis can tolerate the alkalinity of the simulated intestinal juice in a rate of $100 \%$ after 1 and 2 hours incubation. Meanwhile, the organism can tolerate the acidity of the artificial gastric juice in a rate of $100 \%$ after 1 hour and the rate decreased after 2 hours to $70 \%$. Germination of Bacillus spores in the small intestine has been reported in several studies (Cartman et al., 2008). Their beneficiary effect in the animal host may be attributed to the active metabolic mechanism, such as competition with pathogenic bacteria for essential nutrients and/or secretion of antimicrobial substances (Duc et al., 2003). It is worthy to mention that before using a probiotic strain to demonstrate its beneficial effect on animal host; the in vivo and in vitro studies must be investigated (Mingmongkolchai and Panbangred, 2018).

In the present study; in vitro study at dilution $10^{3}$, the count of $C$. perfringens type A reached $2.1 \times 10^{5}$ $\mathrm{cfu} / \mathrm{ml}$, however, when $B$. subtilis was added, the count reduced to $3.0 \times 10^{4} \mathrm{cfu} / \mathrm{ml}$. On the other hand, when $C$. perfringens culture was at $10^{2}$ dilutions, the count reached $2.4 \times 10^{5} \mathrm{cfu} / \mathrm{ml}$ and reduced to $7.0 \times 10^{3} \mathrm{cfu} / \mathrm{ml}$ after treated with $B$. subtilis. Several antimicrobial compounds such as bacteriocins, lipopeptides, bacteriocins like inhibitory substances and surfactin are known to be produced by genus Bacillus members. These compounds are typically active against Grampositive bacterial pathogens, but some display activity against Gram-negative bacterial pathogens as well as fungal pathogens (Kerr, 1999; Teo and Tan, 2005; Khochamit et al., 2015). Moreover, by conducting 
antimicrobial activity of $B$. subtilis against $C$. perfringens, a $10 \mathrm{~mm}$ inhibition zone was produced indicating the antimicrobial efficacy of $B$. subtilis. These results are in agreement with Teo and Tan, (2005) who examined the antimicrobial activity of $B$. subtilis against $C$. perfringens ATCC 13124.

\section{CONCLUSIONS}

Bacillus subtilis is safe and reliable animal probiotic with great potential to be used as an alternative to antimicrobial drugs which is significant in the context of antibiotic abuse in food and animal production. Dietary supplementation of $B$. subtilis in rabbit ration will decrease the bacterial load of pathogens and subsequently improves the growth rate of animals.

\section{Declaration of Competing interest}

On behalf of all authors, I hereby declare that no conflict of interest may interfere with the publication of the manuscript.

\section{REFERENCES}

BARBOSA, T. M., SERRA, C. R., LA RAGIONE, R. M., WOODWARD, M. J. AND HENRIQUES, A. O., 2005. Screening for Bacillus isolates in the broiler gastrointestinal tract. Appl. Environ. Microbial.71:968-978.

BOVERA, F., NIZZA, S., AND MARONO, S. K., 2010. Effect of mannan oligosaccharides on rabbit performance, digestibility and rectal bacterial anaerobic populations during an episode of epizootic rabbit enteropathy. World Rabbit Sci., 18:9-16.

CARTMAN, S.T., LA RAGIONE, R.M., AND WOODWARD, M.J., 2008. Bacillus subtilis spores germinate in the chicken gastrointestinal tract. Appl. Environ.Microbial.74:5254-5258.

CASTANON, J., 2007. History of the use of antibiotics as growth promoters in European poultry feeds. Poult. Sci., 86 2466-2471.

CHEN, W., WANG, J. P., YAN, L. AND HUANG, Y.Q., 2013. Evaluation of probiotics in diets with different nutrient densities on growth performance characteristics in broilers. British Poultry Science, 54, 635-41.

ChENG, G., HAO, H., XIE, S., WANG, X., DAI, M., HUANG, L. AND YUAN, Z., 2014. Antibiotic alternatives: the substitution of antibiotics in animal husbandry. Front. Microbiol., 5:69-83.

CUTTING, S.M., 2011. Bacillus probiotics. Food Microbiol., 28: 214-220.

DUC, L. H., HONG, H. A., BARBOSA, T. M., HENRIQUES, A. O. AND CUTTING, S. M., 2004. Characterization of Bacillus probiotics available for human use. Appl. Environ. Microbiol., 70: 2161-2171.

DUC, L.H., HONG, H. A., FAIRWEATHER, N., RICCA, E. AND CUTTING, S.M. 2003. Bacterial spores as vaccine vehicles. , 71:2810-2818.
GUO, M., WU, F., HAO, G., QI, Q., LI, N., WEI, L. AND CHAI, T., 2017. Bacillus subtilis improves immunity and resistance in rabbits. Frontiers in Immunity, 8:1-13.

GUYARD-NICODEME, M., KEITA, A., QUESNE, S., AMElOT, M., POEZEVARA, T., LEBERRE, B., SANCHEZ, J. AND VESSEUR, P., 2016. Efficacy of feed additives against Campylobacter in live broilers during the entire rearing period. Poult. Sci., 95: 298305.

HAO, H., CHENG, G., IQBAL, Z., AI, X., HUSSAIN, H. I., HUANG, L., DAI, M. AND WANG, Y., 2014. Benefits and risks of antimicrobial use in foodproducing animals. Front. Microbiol., 5:288.

JAYARAMAN, S., THANGAVEL, G., KURIAN, H., MANI, R., MUKKALIL, R. AND CHIRAKKAL, H., 2013. Bacillus subtilis PB6 improves intestinal health of broiler chickens challenged with Clostridium perfringens-induced necrotic enteritis. Poult. Sci., 92:370-374.

JEONG, J. S., AND KIM, I. H., 2014. Effect Of Bacillus Subtilis C-3102. spores as a probiotic feed supplement on growth performance, noxious gas emission, and intestinal microflora in broilers. Poult. Sci.,93:30973103.

JIRAPHOCAKUL, S., SULLIVAN, T.W., AND SHAHANI, K.M., 1990. Influence of a dried Bacillus subtilis culture and antibiotics on performance and intestinal microflora in turkeys. Poult. Sci.69:19661973.

KERR, J. R., 1999. Bacterial inhibition of fungal growth and pathogenicity. Microbiol. Ecol. Health Dis., 11: 129.

KHOCHAMIT, N., SIRIPORNADULSIL, S., SUKON, P. AND SIRIPORNADULSIL, W., 2015. Antibacterial activity and genotyping-phenotyping characteristics of bacteriocin producing Bacillus subtilis KKU213; potential as a probiotic strain. Microbiol. Res., 170: 36.

KNAP, I., KEHLET, A., BENNEDSEN, M., MATHIS, G., HOFACRE, C., LUMPKINS, B., JENSEN, M. AND RAUN, M., 2011. Bacillus subtilis DSM17299 significantly reduces Salmonella in broilers. Poult. Sci., 90: 1690-1694.

LA RAGIONE, R. M., AND WOODWARD, M. J., 2003. Competitive exclusion by Bacillus subtilis spores on Salmonella enteric serotype Enteritidis and Clostridium perfringens in young chickens. Poult. Sci., 94:245-256.

LICOIS, D., COUDERT, P, CERE, N. AND VAUTHEROT, J.F., 2000. Epizootic enterocolitis of the rabbits: a review of current research. Proceedings of the $7^{\text {th }}$ World Rabbit Congress; Valencia, Spain, pp. 187-194.

MINGMONGKOLCHAI, S. AND PANBANGRED, W., 2018. Bacillus probiotics: an alternative to antibiotics for livestock production. J. Appl. Microbiol. 124: 1334-1346.

PHUOC, T. L. AND JAMIKOREN, U., 2017. Effect of probiotic supplement (B. subtilis and Lactobacillus acidophilus) on feed efficiency, growth performance, and microbial population of weaning rabbits. AsianAustralas. J. Anim. Sci.,30(2):198-205.

SIMONEIT, C., BUROW, E., TENHAGEN, B. A. AND KASBOHRER, A., 2014. Oral administration of antimicrobials increases antimicrobial resistance in $E$. 
coli from chicken- a systematic review. Prev. Vet. Med., 118: 1-7.

SPSS 20.0., 2014. Statistical package for social science, SPSS for windows release20.0, Standard version, SPSS Inc. Chicago, IL.

SUllivan, A., EDLUND, C. AND NORD, C.E., 2001. Effect of antimicrobial agent on the ecological balance of human microflora. Lancet Infect. Dis., 1: 101-114.

TEO, A. Y. AND TAN, H., 2005. Inhibition of Clostridium perfringens by a novel strain of Bacillus subtilis isolated from the gastrointestinal tract of healthy chickens. Appl. Environ. Microbiol., 71(8):4185-90.

THIRABUNYANON, M. AND THONGWITTAYA, N., 2012 Protection activity of a novel probiotic strain of B. subtilis against Salmonella Entriditis infection. Res. Vet. Sci., 93:74-81.

VILA, B., FONTGIBELL, A., BADIOLA, I., ESTEVEGARCIA， E., JIMENEZ，G., CASTILLO, M. AND BEUFAU, J., 2009. Reduction of Salmonella enteric var. Enteriditis colonization and invasion by Bacillus cereus var. toyoi inclusion in poultry feeds. Poult. Sci., 88:975-979.

How to cite this article:

Eman, F. Farag and G. A. Abdel-Alim, 2020. The Effect of Bacillus Subtilis on The Bacterial Content In Rabbits Caeci. Journal of Applied Veterinary Sciences, 5(4): $10-16$.

DOI : https://dx.doi.org/10.21608/javs.2020.117995
WILLIS, A. T., 1977. Anaerobic Bacteriology. Clinical and Laboratory Practice. $3^{\text {rd }}$ ed., Butter Worth, London.

YE, X.; LI, P.; YU, Q. AND YANG, Q., 2013. B. subtilis inhibition of enterotoxic Escherichia coli-induced activation of MAPK signalling pathways in Caco-2 cells. Ann. Microbiol., 63: 577-581.

ZHANG, D., RUI, L. AND LI, J., 2012. Lactobacillus reuteri ATCC 55730 and L22 display probiotic potential in vitro and protect against Salmonellainduced pullorum disease in a chick model of infection. Res. Vet. Sci., 93:366-73.

ZHOU, M., WING, H. AND ZE-YANG, L., 2013. Study on resistance to stress factors of Bacillus subtilis from swine intestinal juice. J. Anhui. Agricultural Univer., 40: $519-522$. 